\title{
Database on local environmental conditions and biodiversity in fish ponds in Midden-Limburg, Belgium
}

Pieter Lemmens, Joachim Mergeay, Dirk Ercken, Tom De Bie, Jeroen Van Wichelen, Steven A.J. Declerck \& Luc De Meester
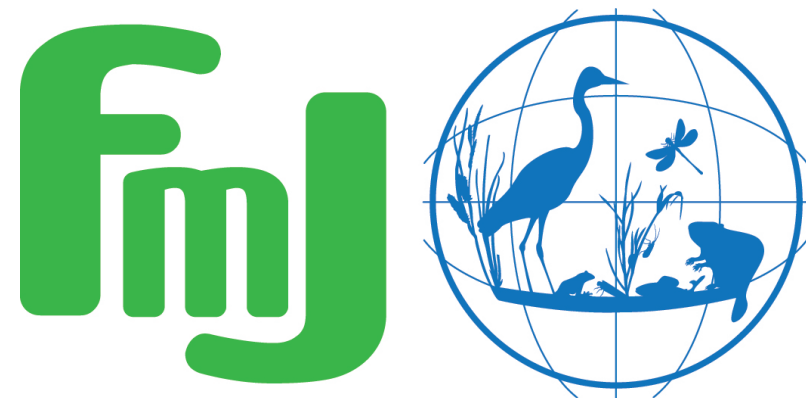

Freshwater Metadata Journal 



\title{
Database on local environmental conditions and biodiversity in fish ponds in Midden-Limburg, Belgium
}

\author{
Pieter Lemmens ${ }^{1}$, Joachim Mergeay ${ }^{3}$, Dirk Ercken ${ }^{1}$, Tom De Bie ${ }^{1}$, Jeroen Van Wichelen ${ }^{3}$, \\ Steven A.J. Declerck ${ }^{2}$ \& Luc De Meester ${ }^{1}$ \\ 1 Laboratory of Aquatic Ecology, Evolution and Conservation, Leuven, Belgium; corresponding author: pieter.lemmens@kuleuven.be \\ 2 Departement of Aquatic Ecology, Institute of Ecology (NIOO-KNAW), Wageningen, The Netherlands \\ 3 Research Institute for Nature and Forest, Brussels, Belgium
}

Please cite this paper as follows: Lemmens, P., Mergeay, J., Ercken, D., De Bie, T., Van Wichelen, J., Declerck, S.A.J. \& De Meester, L., 2017. Database on local environmental conditions and biodiversity in fish ponds in Midden-Limburg, Belgium. Freshwater Metadata Journal 27: 1-8.

https://doi.org/10.15504/fmj.2017.27

Received: 2017-08-11 / Published: 2017-10-11

\section{Keywords}

fish ponds, occurrences, pond managment, Belgium

\section{Short description of the dataset/summary}

The Midden-Limburg pond dataset contains data on local habitat conditions and taxonomic community composition of multiple aquatic organism groups (phytoplankton, zooplankton, aquatic vegetation, macro-invertebrates and fish) from 38 interconnected fish ponds in the fish pond complex Midden-Limburg (Limburg, Belgium). The selection of fish ponds represents five different pond management types.

\section{General information}

dataset entry ID:

SF_12

name of the dataset:

full name of the dataset:

Midden-Limburg Fish Ponds Survey

dataset short name:

type of dataset:

Midden-Limburg Survey

species (taxonomic group) per site database including environmental information

data type:

point data/observation data

science keywords according to GCMD:

topic:

Biosphere, Biological Classification, Land Surface, Terrestrial Hydrosphere

ISO topic category according to ISO 19115:

Biota, Environment, Inland Waters

own science keywords:

fish ponds, occurrences, environmental conditions, pond management, Belgium 


\section{Technical and administrative specifications}

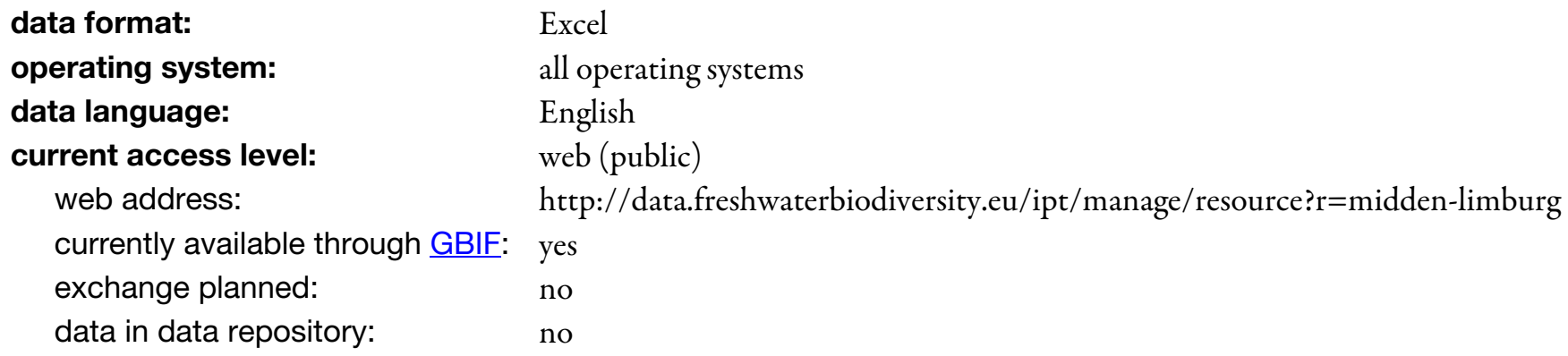

Do you plan to publish the data on the Freshwater Biodiversity Data Portal:

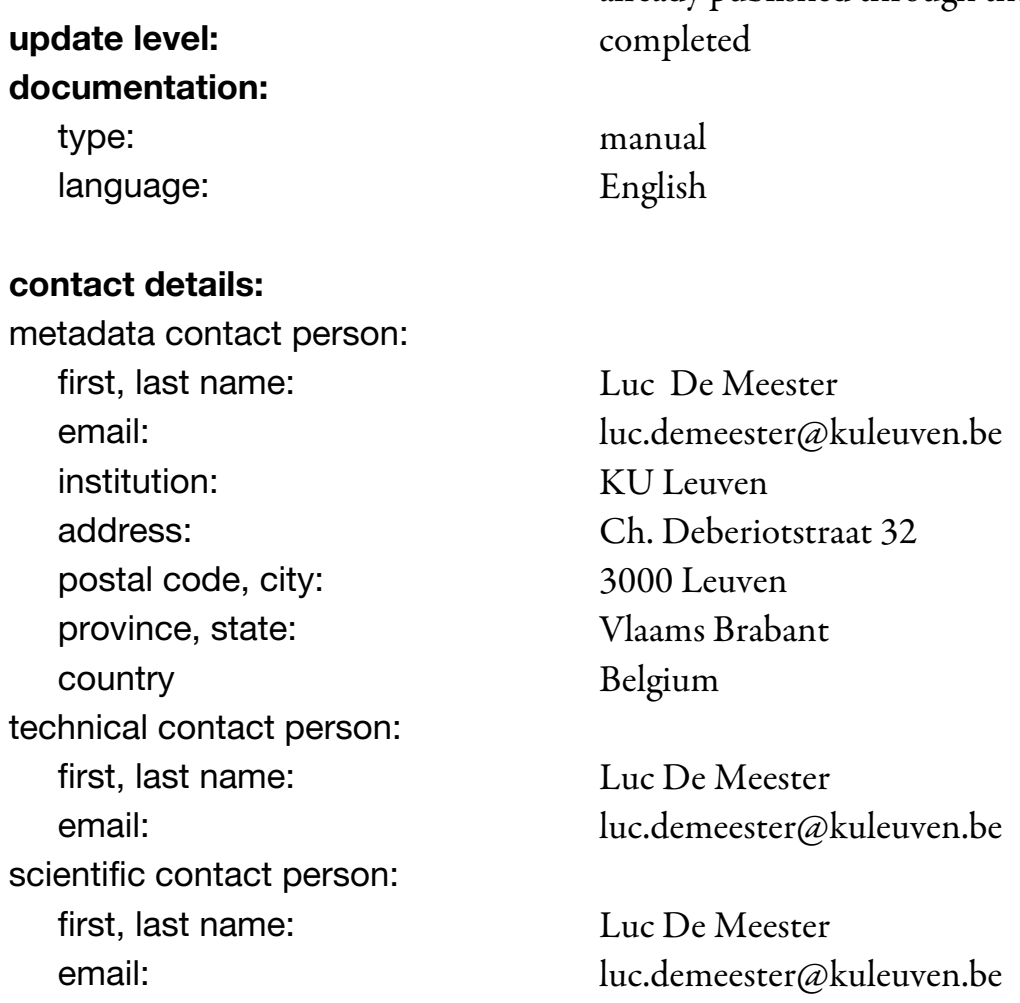

\section{Intellectual property rights and citation}

dataset creator (data compiler):
contact name:
Pieter Lemmens
contact email:
pieter.lemmens@kuleuven.be
contact institution:
KU Leuven

\section{data contributors to/owners of this dataset:}

number:

multiple

6

\section{data contributor/owner 1:}

contact name:

Pieter Lemmens

contact email:

pieter.lemmens@kuleuven.be

contact institute:

KU Leuven

criteria for using this part of the dataset:

The dataset is publicly available (data portal, data archive) and can be used without restrictions, but dataset creator/data contributors must be informed prior to publication. Data must be acknowledged and cited correctly. 


\section{data contributor/owner 2:}

contact name:

contact email:

contact institute:

criteria for using this part of the dataset:
Joachim Mergeay

joachim.mergeay@inbo.be

INBO

The dataset is publicly available (data portal, data archive) and can be used without restrictions, but dataset creator/data contributors must be informed prior to publication. Data must be acknowledged and cited correctly.

data contributor/owner 3:

contact name:

Tom De Bie

contact email:

contact institute:

tom.debie@kuleuven.be

KU Leuven

criteria for using this part of the dataset:

The dataset is publicly available (data portal, data archive) and can be used without restrictions, but dataset creator/data contributors must be informed prior to publication. Data must be acknowledged and cited correctly.

\section{data contributor/owner 4:}
contact name:
Jeroen Van Wichelen
contact email:
contact institute:
jeroen.vanwichelen@inbo.be
INBO

criteria for using this part of the dataset:

The dataset is publicly available (data portal, data archive) and can be used without restrictions, but dataset creator/data contributors must be informed prior to publication. Data must be acknowledged and cited correctly.

data contributor/owner 5:
contact name:
Luc De Meester
contact email:
luc.demeester@kuleuven.be
contact institute:
KU Leuven

criteria for using this part of the dataset:

The dataset is publicly available (data portal, data archive) and can be used without restrictions, but dataset creator/data contributors must be informed prior to publication. Data must be acknowledged and cited correctly.

\section{data contributor/owner 6:}

$\begin{array}{ll}\text { contact name: } & \text { Steven A.J. Declerck } \\ \text { contact email: } & \text { S.Declerck@nioo.knaw.nl } \\ \text { contact institute: } & \text { NIOO }\end{array}$

criteria for using this part of the dataset:

The dataset is publicly available (data portal, data archive) and can be used without restrictions, but dataset creator/data contributors must be informed prior to publication. Data must be acknowledged and cited correctly.

citation of this dataset:

author(s):

Lemmens, P., De Wever, A., Mergeay, J., De Bie, T., Ercken, D., Van Wichelen, J., Declerck, S.A.J. \& De Meester, L.

title and journal (name, number, pages):

Biodiversity in interconnected Belgian man-made fish ponds representing

different pond management types

year:

2017

doi:

https://doi.org/10.13148/fzynim

\section{citation of the metadata:}

author(s):

Lemmens, P., Mergeay, J., Ercken, D., De Bie, T., Van Wichelen, J., Declerck, S.A.J. \& De Meester, L. 
title and journal (name, number, pages):

Database on local environmental conditions and biodiversity in fish ponds in Midden-Limburg, Belgium. Freshwater Metadata Journal 27: 1-8

year: 2017

doi: https://doi.org/10.15504/fmj.2017.27

dataset related references:

reference 1:

author(s):

title:

Lemmens, P., Declerck, S.A.J, Mergeay, J., De Bie, T., Van Wichelen, J. \& De Meester, $\mathrm{L}$.

How to maximally support local and regional biodiversity in applied conservation? Insights from pond management. PLoS ONE 8(8): e72538

year: 2013

doi:

https://doi.org/doi:10.1371/journal.pone.0072538

reference 2:

author(s):

title:

year:

Lemmens, P., Mergeay, J., Van Wichelen, J., De Meester, L. \& Declerck, S.A.J The impact of conservation management on the community composition of multiple organism groups in eutrophic interconnected man-made ponds. PLoS ONE 10(9): e0139371.

doi: 2015

https://doi.org/doi:10.1371/journal. pone.0139371

\section{General data specifications}

regional coverage of the dataset:

spatial extent of the dataset:

regional

continents:

Europe

spatial extent (bounding coordinates):

southernmost latitude $\left[{ }^{\circ}\right]$ :

51801.47

northernmost latitude $\left[^{\circ}\right]$ :

52315.24

westernmost longitude $\left[{ }^{\circ}\right]$ :

505824.47

easternmost longitude $\left[^{\circ}\right]$ :

505969.98

countries:

Europe: Belgium

world climatic regions according to Köppen:

Group D: continental/microthermal climate

freshwater ecoregions of the world (FEOW) according to WWF:

Europe: Central \& Western Europe

European ecoregions according to Illies (WFD):

ecosystem type:

covered timeframe:

\section{Site specifications}

coordinate system/grid data:

datum (e.g. WGS84):

grid data available:

site coding:

site coding available:
Western Plains (ER13)

lakes/ponds

$2006-2007$ latitude/longitude, format: DMS

projected, UTM

WGS84

no

yes, alphanumerical 
number of digits:

example:

number of sites:

exact number of sites:
3

$\mathrm{BK} 7, \mathrm{~K} 1$

$<100$

38

\section{Climate and environmental data}

climate related data:

environmental data:

available parameters per site:

comments:

physico-chemical data:

other physico-chemical parameters:

Percentage of pond surface covered with submerged, floating and emergent vegetation, and pond size.

availability of physico-chemical data, if there is more than one sample per site: mean values per site

stressors influencing the sites:

reference sites available:

no

\section{Biological data}

biological data origin:

from sampling,

TWOL research project (LIM/AMINAL/AN/LIM/2004/10)

organism group addressed:

\section{Sample specifications/sample resolution}

\section{fish:}

sample information:

covered timeframe: $\quad 2006-2007$

historical data: no

palaeo data: no

season: summer

temporal resolution/frequency of sampling:

taxonomic resolution:

per year

level: $\quad$ species

taxonomic coding:

taxalist according to: FishBase 


\section{sample specifications:}

type:

replicate samples:

comments: quantitative (abundance data)

no

For details see Lemmens P., Declerck S.A.J, Mergeay J., De Bie T., Van Wichelen J. \& De Meester L., 2013. How to Maximally Support Local and Regional Biodiversity in Applied Conservation? Insights from Pond Management. PLoS ONE 8(8): e72538. doi:10.1371/journal.pone.0072538

\section{macro-invertebrates: sample information:}

covered timeframe:

$2006-2007$

historical data:

no

palaeo data:

no

season:

spring, summer

temporal resolution/frequency of sampling:

time series data:

per year

no

\section{taxonomic resolution:}

level:

comments:

\section{taxonomic coding:}

taxalist according to: reference(s):

\section{sample specifications:}

type:

comments:

\section{zooplankton:}

\section{sample information:}

covered timeframe:

historical data:

palaeo data:

season:

time series data:

\section{taxonomic resolution:}

level:

comments:

\section{taxonomic coding:}

taxalist according to:

reference(s):

\section{sample specifications:}

type: other

Ephemeropterans, Hemiptera and Mollusca were identified to species level. Determination of Diptera was done up to family level. Other organisms were only sorted to higher taxomic levels and counted (Acari and Hirudinea to subclass, Trichoptera and Lepidoptera to order).

De Pauw N. \& Vannevel R. (1991)

De Pauw N. \& Vannevel R., 1991. Macro-invertebraten en waterkwaliteit. Antwerpen: Stichting Leefmilieu.

quantitative (abundance data)

For details see Lemmens P., Declerck S.A.J, Mergeay J., De Bie T., Van Wichelen J. \& De Meester L., 2013. How to Maximally Support Local and Regional Biodiversity in Applied Conservation? Insights from Pond Management. PLoS ONE 8(8): e72538. doi:10.1371/journal.pone.0072538

\author{
$2006-2007$ \\ no \\ no \\ summer \\ no
}

other

Cladocera were identified to species level using Flössner (2000) and counted. Daphnia galeata (Sars) and D. longispina (Müller) were considered as one taxon. Copepoda were divided in two main groups (Cyclopoids and Calanoids) and counted.

Flössner D. (2000)

Flössner D., 2000. Die Haplopoda und Cladocera Mitteleuropas Leiden.

Backhuys Publishers.

quantitative (abundance data) 
replicate samples:

comments:

\section{phytoplankton: \\ sample information: \\ covered timeframe: \\ historical data: \\ season: \\ time series data: \\ taxonomic resolution: \\ level: \\ taxonomic coding: \\ taxalist according to: \\ reference(s): \\ sample specifications: \\ type: \\ comments:}

\section{macrophytes: \\ sample information:}

covered timeframe:

historical data:

palaeo data:

season:

temporal resolution/frequency of sampling:

time series data:

\section{taxonomic resolution:}

level:

taxonomic coding:

taxalist according to:

reference(s):

\section{sample specifications:}

type:

comments:

no

no

no

summer

per year

no

species
For details see Lemmens P., Declerck S.A.J, Mergeay J., De Bie T., Van Wichelen J. \& De Meester L., 2013. How to Maximally Support Local and Regional Biodiversity in Applied Conservation? Insights from Pond Management. PLoS ONE 8(8): e72538. doi:10.1371/journal.pone.0072538

\author{
$2006-2007$ \\ no \\ summer \\ no \\ genus
}

John et al. (2002)

John D.M., Whitton B.A., Brook A.J., 2002. The freshwater algal flora of the British isles. Cambridge: Cambridge University Press.

semi-quantitative

For details see Lemmens P., Declerck S.A.J, Mergeay J., De Bie T., Van Wichelen J. \& De Meester L., 2013. How to Maximally Support Local and Regional Biodiversity in Applied Conservation? Insights from Pond Management. PLoS ONE 8(8): e72538. doi:10.1371/journal.pone.0072538

$2006-2007$

Lambinon et al. (1983)

Lambinon J., De Langhe J.-E. , Delvosalle L., Duvigneaud J., 1983. Flora van België, het Groothertogdom Luxemburg, Noord-Frankrijk en de aangrenzende gebieden (Pteridofyten en Spermatofyten). Een uitgave van het Patrimonium van de Nationale Plantentuin van België.

semi-quantitative

For details see Lemmens P., Declerck S.A.J, Mergeay J., De Bie T., Van Wichelen J. \& De Meester L., 2013. How to Maximally Support Local and Regional Biodiversity in Applied Conservation? Insights from Pond Management. PLoS ONE 8(8): e72538. doi:10.1371/journal.pone.0072538 


\title{
Other specifications
}

GIS layers, shape files related to the dataset:

\author{
no data available \\ availability of photos: \\ no \\ availability of maps: \\ no \\ quality control procedures: \\ Were any quality control procedures applied to your dataset? \\ yes \\ quality control protocols and comments: \\ Species names were checked using the GBIF species list. In addition, the quality \\ of data has been checked with the phwhip validator.
}

\section{Acknowledgements}

The authors acknowledge the Agency for Nature and Forests for funding the Midden-Limburg Fish Ponds Survey via a national TWOL project (LIM/AMINAL/AN/LIM/2004/10), and the Belgian Science Policy (Belspo) for funding the SAFRED project (Saving freshwater biodiversity research data - 2015-2018) that allowed processing and publishing the data.

\section{References}

Lemmens P., Declerck S.A.J, Mergeay J., De Bie T., Van Wichelen J. \& De Meester L., 2013. How to Maximally Support Local and Regional Biodiversity in Applied Conservation? Insights from Pond Management. PLoS ONE 8(8): e72538 https://doi.org/10.1371/journal.pone.0072538

Lemmens P., Mergeay J., Van Wichelen J., De Meester L. \& Declerck S.A.J, 2015. The impact of conservation management on the community composition of multiple organism groups in eutrophic interconnected man-made ponds. PLoS ONE 10(9): e0139371. https://doi.org/10.1371/journal. pone.0139371 